Med Princ Pract 2011;20:200

DOI: $10.1159 / 000321277$

\section{Is CEA Better than CYFRA 21-1 in the Monitoring of Squamous Cell Lung Cancer Progression?}

\author{
Giuseppe Lo Russo, Fabrizio Franchi, Patrizia Seminara \\ Department of Clinical Medicine, University of Rome \\ 'La Sapienza', Rome, Italy
}

CEA is presently considered the best serum tumor marker (STM) in monitoring the progression of several tumors, particularly colorectal cancer which has metastasized [1]. However, in the follow-up of squamous lung cancer the detection of CYFRA 21-1 has been shown to be better than CEA [2-4].

In 45 patients with nonsurgically resectable squamous lung cancer, followed in our center with a median observation of 12 months (range 6-24), CEA and CYFRA 21-1 levels were measured every 3 months in the postchemotherapeutic period while the disease was in remission or stabilized. If an STM showed an increase of $>10 \%$, when compared with the previous measurement, its level was controlled 30 days later. This evaluation schedule, however, was not performed if the patient presented a possible nonspecific cause of marker elevation such as any inflammatory process.

STM detection was established with an immunoenzymatic method for CEA (CanAg CEA enzyme immunoessay kit, Fujirebio Diagnostics, Goteborg, Sweden) while ELSA-CYFRA 21-1 kit (CIS Bio International, Gif-sur-Yvette, France) was employed for CYFRA 21-1.

A disease relapse was evidenced by computed tomography in 38 patients. CEA or CYFRA 21-1 increased in 36 patients; 2 patients presented with tumor relapse in the absence of elevation of either or both STMs. We have no data concerning CEA and CYFRA 21-1 specificity because the STM monitoring was not performed when a nontumoral origin could produce its serum increase. The total number of cases with a local progression was 18 . In these subjects the progression was evidenced by CEA in 12 and by CYFRA $21-1$ in 10. Twenty patients had distant metastases; 16 were observed with CEA and 10 with CYFRA 21-1.

In our hands the single sensitivity of CYFRA 21-1, as a diagnostic tool of tumor progression, was $52.6 \%$ while the sensitivity of CEA was $73.7 \%$ and that of the 2 associated STMs was $94.7 \%$.
With the present series of patients the difference in sensitivity between CEA and CYFRA 21-1 was not significant $(\mathrm{p}<0.15)$, although monitoring with CEA seemed to be better. The combination of the two STMs, however, was significantly more reliable $(p<0.0001)$ than the use of CYFRA 21-1 only.

Our data did not confirm the preference for CYFRA 21-1 reported previously [2-6] in revealing squamous lung cancer growth or spread. The combination of the two STMs was better than the use of only CEA or CYFRA 21-1.

\section{References}

1 Duffy MJ, van Dalen A, Haglund C, Hansson L, Holinski-Feder E, Klapdor R, Lamerz R, Peltomaki P, Sturgeon C, Topolcan O: Tumour markers in colorectal cancer: European Group on Tumour Markers (EGTM) guidelines for clinical use. Eur J Cancer 2007;43:1348-1360.

2 Brechot JM, Chevret S, Nataf J, Le Gall C, Frétault J, Rochemaure J, Chastang C: Diagnostic and prognostic value of CYFRA 21-1 compared with other tumour markers in patients with non-small cell lung cancer: a prospective study of 116 patients. Eur J Cancer 1997;3:385-391.

$\checkmark 3$ Pastor A, Menendez R, Cremades M, Pastor V, Llopis R, Aznar J: Diagnostic value of SCC, CEA and CYFRA 21-1 in lung cancer: a Bayesian analysis. Eur Respir J 1997;10:603-609.

4 Kulpa J, Wojcik E, Reinfuss M, Kołodziejski L: Carcinoembryonic antigen, squamous cell carcinoma antigen, CYFRA 21-1, and neuron-specific enolase in squamous cell lung cancer patients. Clin Chem 2002;11: 1931-1937.

5 Ebert W, Dienemann H, Fateh-Moghadam A, Scheulen M, Konietzko N, Schleich T, Bombardieri E: Cytokeratin 19 fragment CYFRA 21-1 compared with carcinoembryonic antigen, squamous cell carcinoma antigen and neuron-specific enolase in lung cancer: result of an international multicentre study. Eur J Clin Chem Clin Biochem 1994;32: 189-199.

-6 Wieskopf B, Demangeat C, Purohit A, Stenger R, Gries P, Kreisman H, Quoix E: CYFRA 21-1 as a biologic marker of non-small cell lung cancer: evaluation of sensitivity, specificity and prognostic role. Chest 1995; 108:163-169.

Fabrizio Franchi

Department of Clinical Medicine

University of Rome 'La Sapienza'

IT-00185 Rome (Italy)

Tel. +39 649970601, Fax +39649970308

E-Mailfabriziofranchi@interfree.it

\begin{tabular}{ll}
\hline KARGER & (c) 2011 S. Karger AG, Basel \\
1011-7571/11/0202-0200 $\$ 38.00 / 0$ \\
Fax +41 61306 1234 \\
$\begin{array}{l}\text { E-Mail karger@karger.ch } \\
\text { www.karger.com }\end{array}$ & $\begin{array}{l}\text { Accessible online at: } \\
\text { www.karger.com } / \mathrm{mpp}\end{array}$
\end{tabular}

